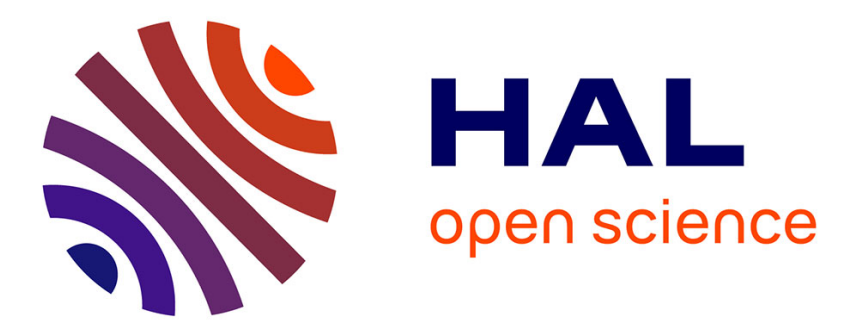

\title{
What's that got to do with the price of fish? Buyers behavior on the Ancona fish market
}

Mauro Gallegati, Gianfranco Giulioni, Alan Kirman, Antonio Palestrini

\section{To cite this version:}

Mauro Gallegati, Gianfranco Giulioni, Alan Kirman, Antonio Palestrini. What's that got to do with the price of fish? Buyers behavior on the Ancona fish market. 2010. halshs-00545129

\section{HAL Id: halshs-00545129 \\ https://shs.hal.science/halshs-00545129}

Preprint submitted on 9 Dec 2010

HAL is a multi-disciplinary open access archive for the deposit and dissemination of scientific research documents, whether they are published or not. The documents may come from teaching and research institutions in France or abroad, or from public or private research centers.
L'archive ouverte pluridisciplinaire HAL, est destinée au dépôt et à la diffusion de documents scientifiques de niveau recherche, publiés ou non, émanant des établissements d'enseignement et de recherche français ou étrangers, des laboratoires publics ou privés. 


\section{GREQAM}

Groupement de Recherche en Economie Quantitative d'Aix-Marseille - UMR-CNRS 6579

Ecole des Hautes études en Sciences Sociales Universités d'Aix-Marseille II et III
Document de Travail $n^{\circ} 2010-54$

What's that got to do with the price of fish? Buyers behavior on the Ancona fish market

\author{
Mauro Gallegati \\ Gianfranco Giulioni \\ Alan Kirman \\ Antonio Palestrini
}

December 2010 


\title{
What's that got to do with the price of fish? Buyers behavior on the Ancona fish market
}

\author{
Mauro Gallegati ${ }^{\mathrm{a}}$, Gianfranco Giulioni ${ }^{\mathrm{b}, *}$, Alan Kirman ${ }^{\mathrm{c}}$, Antonio \\ Palestrini $^{\mathrm{d}}$ \\ ${ }^{a}$ SIEC and DEA, Polytechnic University of Marche, Ancona, Italy \\ ${ }^{b}$ DMQTE, University of Chieti-Pescara, Italy. \\ ${ }^{c}$ EHESS, GREQAM, Marseille, France. \\ ${ }^{d}$ SGSS, University of Teramo, Italy.
}

\begin{abstract}
In this paper we analyze the Ancona wholesale fish market (MERITAN) where transactions take place in three simultaneous Dutch auctions. Our objective is to characterize the behavior of market participants and, in particular, buyers in such a market structure. Our analysis of the data shows that buyer-seller relationships are less important than in a pairwise bargaining market such as the Marseille Fish market but that a significant amount of "loyalty" is still present under the auction mechanism. We provide an explanation of the "declining price paradox" for the fish market of Ancona by linking the rule used by the buyers to set their bid to the relationship between the variation in the price of the last transactions in the day and the quantity of fish available on that day. In fact, the average price tends to increase for last transactions on days characterized by limited supply of fish.
\end{abstract}

Keywords: wholesale fish market, Dutch auction

JEL classification: D44, Q22

\section{Introduction}

A basic question in economics is how the behavior of market participants is affected by the way in which the market is organized. In much of the

\footnotetext{
*Corresponding author

Email address: g.giulioni@unich.it (Gianfranco Giulioni)
} 
microeconomic literature the market is simply considered as an anonymous price setting mechanism which matches demand and supply. However, it has been argued that particular forms of market organization may favor one side of the market (for an early discussion see Vernon Smith (1964)). ${ }^{1}$ For example, auctions should in principle extract the maximum revenue from buyers and thus are considered to favor sellers. There is a debate as to who is favored in other market organizations, such as posted price markets or those in which pairwise negotiation obtains (see Myerson and Satterthwaite, 1983; Bulow and Klemperer, 1996; Lu and McAfee, 1996; Progrebna, 2006). This paper will analyze the behavior of the participants in the Ancona fish market, for which we have detailed data for all the transactions made over a period of seven months.

This market is organized as three simultaneous Dutch (descending price) auctions. We establish a number of salient facts about the behavior of the buyers and the auctioneer and compare them, where possible, with those revealed by the few existing studies on other fish markets.

Before doing this however, we have to answer an obvious question, why choose a fish market? The answer is relatively simple, the particular interest of fish markets for economists is that they exhibit two features which make them a natural subject for economic analysis. Firstly, fish is a perishable good and the fact that, as a result, stocks cannot be carried over makes the formal analysis of the market simpler. Secondly the organization of such markets varies from location to location with little obvious reason. In Iceland, for example there are 32 auctions, 18 of these are English, i.e. rising price and 14 are Dutch, i.e. descending price. At Lorient in France, fish is sold through a combination of pairwise trading and auction, whilst at Sete it is sold by Dutch auction and at nearby Marseille by pairwise trading. The fish market in Sydney is conducted as two simultaneous Dutch auctions, whilst that at Ancona has three such auctions. The comparison of the outcomes under different forms of organization is an obvious research topic but one which has not received much attention to date. This paper will make a modest contribution in that direction by relating the facts from the Ancona market to those from earlier studies of fish markets.

Fish markets have a long tradition in the economic literature. The first

\footnotetext{
${ }^{1}$ Nowadays there seems to be an increasing interest in the role of market organization and its effect on prices, (see List, 2004), though this is still a very limited development.
} 
serious theoretical debate on the subject was that between John Stuart Mill (1869) and Thornton (1870). The question at issue was the nature of the prices charged for the same type of fish during auctions. The two points of view were firstly that there were either several possible equilibria or no equilibrium prices at all whilst the opposing point of view proposed that what was observed were out of equilibrium or disequilibrium prices. This debate was reopened by Negishi (1986) and was followed by a discussion by Ekelund and Thommesen (1989) and a reply by Negishi (1989). What emerged as the central issue of this debate was the interpretation of the notion of an equilibrium price on a market such as that of fish. ${ }^{2}$

Since, as we have said, fish is essentially perishable, markets such as Ancona can be considered as ones in which, in each period, stocks are fixed and the buyers' strategic variable are their bids. The auctioneer's strategy involves choosing the price at which he starts the auction, and the sellers choose the price at which they withdraw their fish from the auction. The set of strategies depends, of course, on the sort of market organization which is being considered. For example in markets such as Marseille the prices proposed by the sellers and the counter offers made by the buyers are the strategies. Whilst, as we have said, since, in markets such as Ancona, Sydney or Sete the aggregate stocks available on a day are fixed, the strategic behavior of the auctioneer and of the sellers is very limited.

The overall goal of this paper is to investigate how much we can extract from the data (section 3) concerning the behavior of the market participants in a rather particular form of market organization. In this section we basically analyze two points, the price behavior and the buyers' and sellers' characteristics and their relationship with each other. From this, we go on to examine whether a certain number of the features found in other fish markets are also present in the Ancona market,

In subsections 3.1 and 3.2 we will test for the "declining price paradox" found by a number of authors such as Ashenfelter (1989) and McAfee and

\footnotetext{
${ }^{2}$ As a curiosity, the celebrated studies on prey-predator dynamics had in some way the analysis of fish markets. Vito Volterra was led to study the interactions among predators and preys by his son-in-law Umberto D'Ancona who studied the fish market in Trieste. This is explicitly acknowledged in Volterra's 1926 seminal paper. Due to the relatively short period covered by our data, in this paper we do not take into account biological interactions which have an effect on the relative abundance of species and on the price of fish as well in the long run.
} 
Vincent (1993) in auctions with multiple units. ${ }^{3}$ Both Marshall and Pareto argued that this feature is present in fish prices but, for example it does not seem to be present in the data from Marseille (see Hardle and Kirman, 1995).

In subsection 3.3 we will test for another feature of fish markets found by Weisbuch et al. (2000), the loyalty of buyers to particular sellers. On the Marseille fish market which they study, buyers and sellers meet face to face and some buyers become extremely loyal to certain sellers whilst others exhibit no loyalty at all. In our context the equivalent observation would correspond to certain buyers always buying their fish from the same vessel whilst others buy from all the vessels. What our data show is that even though the catches of each vessel are put on a belt sequentially in random order, loyalty is present and the buyers care about the identity of the sellers. In section 3.4 the next feature that we examine is that of the participants' performance. In other words, do some buyer or sellers do systematically better than others in terms of the prices that they obtain? We find that this is the case. Section 3.5 analyzes jointly loyalty and price performances of buyers. However, the relationship is the opposite of that found on the Marseille Fish market, that is loyal buyers obtain better prices in the Ancona Dutch auction.

Section 4 concludes.

\section{Description of MERITAN}

The MER.IT.AN ("MERcato ITtico ANcona" which is the Italian language expression which means Fish market of Ancona) is open 4 days a week (Tu.-Fr.; 3.30-7.30 a.m.). It consists of 3 simultaneous Dutch auctions with about 15 transactions in total per minute. The total value of the fish sold amounts to 25 millions $€$ per year.

All the vessels unload their fish the evening before the auction. In the morning, each type of fish is arranged in cases of about 5-7 Kilograms. Each morning the vessels are randomly assigned to one of three conveyor belts and the market employees start putting the cases from that vessel on it. When the selected seller puts a case on the belt the type of fish, the weight and the vessel that caught the fish are shown on the screen. Then, the price display is set (the auctioneer decides the initial price) and the price progressively

\footnotetext{
${ }^{3}$ The prediction of traditional auction theory can be found in McAfee and McMillan (1987).
} 
declines as the case moves toward the end of the belt. Buyers watch the three displays and can bid on one or more of them. In such Dutch auctions the first person to push the button corresponding to a belt, at the price that has been reached for the case on that belt, wins the auction.

The data we use in the paper correspond to the fish sold on one of the three conveyor belts. They cover the period from the $19^{\text {th }}$ September 2002 to the $28^{\text {th }}$ of May 2003. The database represents 53555 transactions for a total weight of $360115 \mathrm{~kg}$. During this period 70 sellers and 149 buyers exchanged 110 transaction classes on this specific conveyor belt (data for the whole market are more comprehensive). Note that what we call a transaction class is different from a species. In fact, in this market, the items sold are recorded using a more detailed classification than would be obtained by considering only species. So, as an example, the species sole has three transaction classes: big, medium and small sole, defined by the length of the fish (see the second column of table 1 for further examples of transaction classes).

The data for all the transactions are collected daily and stored on the market computer. For each case traded the data reports

- The day, month and time (hour and minute) of the transaction.

- The weight.

- The price per kilo and total.

- The identification number of the seller (vessel).

- The identification number of the buyer.

- The transaction class (T.C. hereafter) and its identification number.

Table 1 reports the number of transactions and the total weight for the main TCs, buyers and sellers. We could also have used the total value traded by each market participant but this would not change the overall picture.

To complete the description of the market we examine buyers and sellers size distributions. We define the size as the weight of the fish bought or sold by the agents. As shown in figure 1, there is no dominant size among the sellers while the buyers are clustered on the smaller sizes. The distribution of buyers has a clear peak while that of sellers is rather flat. On the other hand it is evident that there are a few very large buyers (the solid lines are 


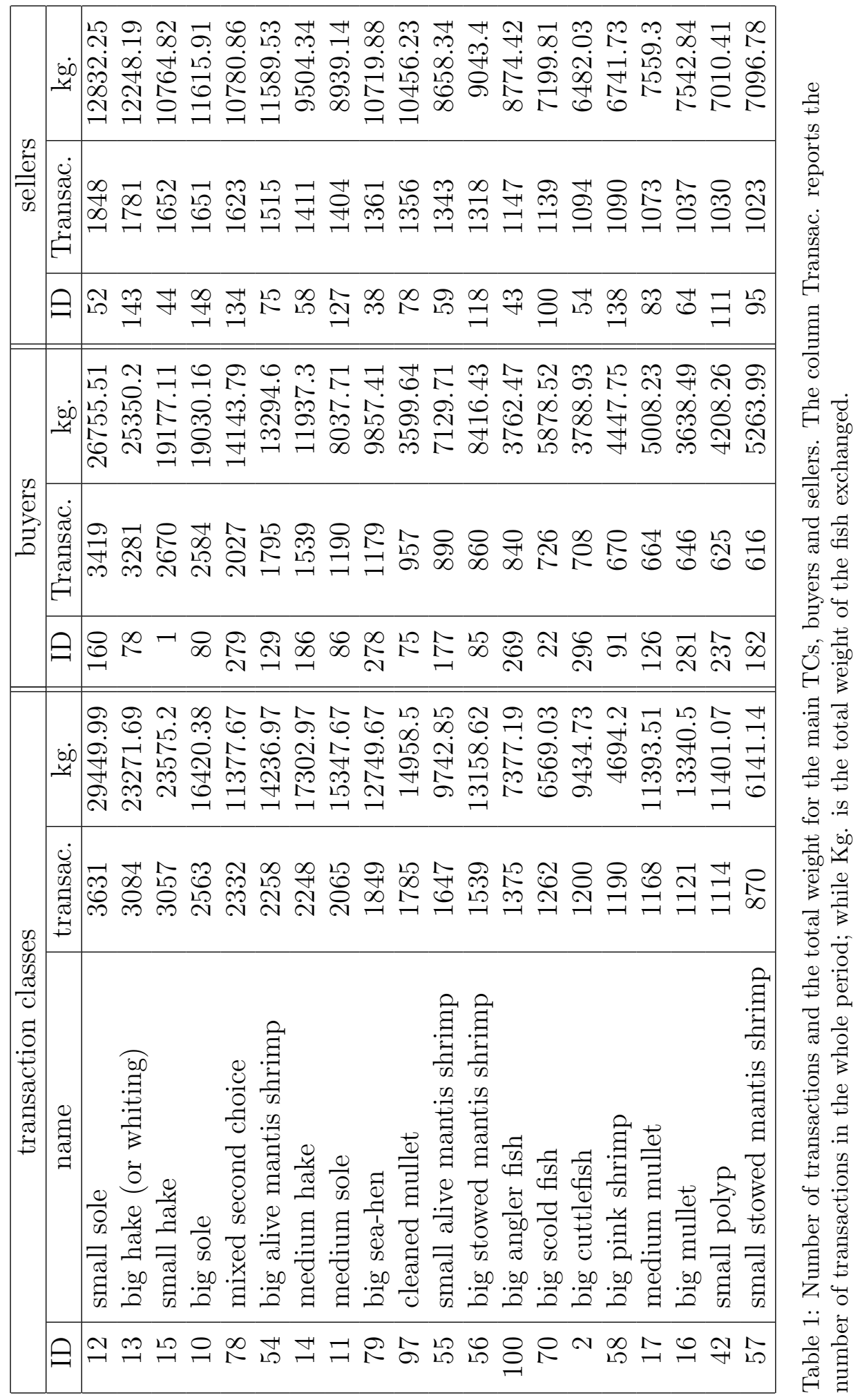



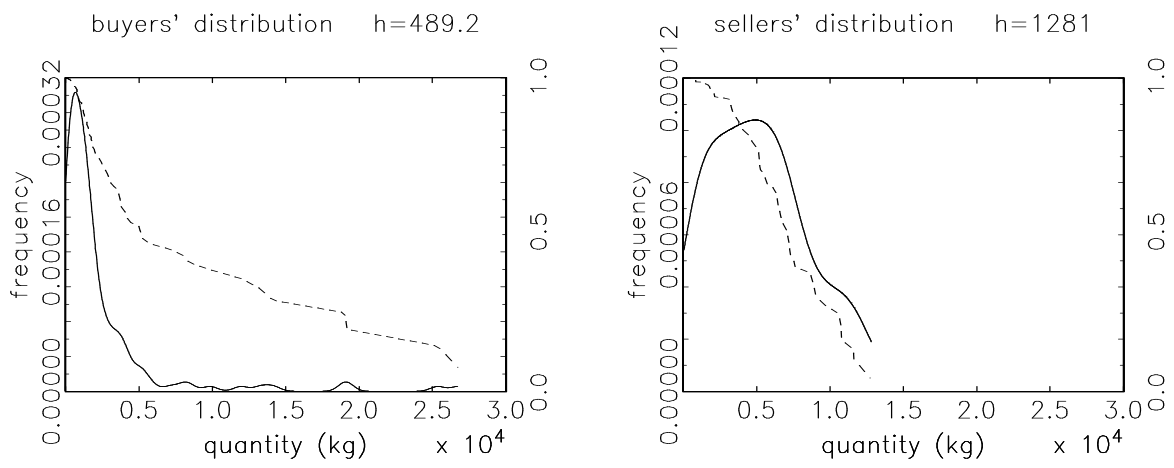

Figure 1: Buyers, and Sellers, size distributions. Solid line and left vertical axes: nonparametric estimation of the density. Dashed line and right vertical axes: empirical complementary cumulative distribution function.

obtained non parametrically using kernel smoothing techniques with a Gaussian kernel, where $h$ is the bandwidth; the dashed line is the complementary empirical cumulative distribution function and its level can be read using the right vertical axis).

\section{The empirical evidence}

In this subsection we take a closer look at two questions. First, we analyze the way in which prices are formed and the dynamics of this process. Second we investigate the effect of the auction mechanism. In this second context, the two main questions are: $i$ ) does the auction destroy buyer-seller relationships? ii) are there buyers (sellers) who obtain lower, (higher) prices than others?

\subsection{Price-quantity relationship}

If we accept the findings of auction theory we should expect that on days when there is less fish on the market the buyers would buy at a higher price than on those days when more fish is available and the price of the fish would remain constant over the day. This, of course supposes that buyers are informed as to the total quantity available which is not, in fact, the case. Were this result to hold we should observe, over the whole period, a 
downward sloping relationship between price and quantity. However, even if the theory does not correctly describe the behavior of individual market participants, it is still possible that such a price-quantity relation holds at the aggregate level as was observed in Hardle and Kirman (1995). So, first of all we checked for the existence of a negative relationship at the aggregate level, between price and quantity. For this kind of test it is not sufficient to plot the data of each transaction. Recall that the fish are sorted into cases with more or less equal weights, this means that a plot of quantity (weight) and price for each transaction would yield an inelastic relationship (a vertical line in the price-quantity plane) just because the quantity cannot change freely. To avoid this problem we use the average daily price, $P m$, and the total daily quantity, qt (these quantities relate to all the TCs).

To analyze the aggregate price-quantity relationship it is better to difference the series since the daily average price $P m$ (and also the daily quantity $q t$, even though this is less evident; see the unit root tests below) is a nonstationary process (because fish prices rise over time; see figure 2, left panel). The value of the augmented Dickey-Fuller test (ADF; 4 lags are used to compute the unit root test) for the daily average price $P m$ is equal to -1.37 . The critical values for the ADF test are -2.888 (5\%), -3.491 (1\%) so the unit root hypothesis for $\mathrm{Pm}$ is not rejected. But it is rejected for the differenced series DPm (ADF test $=-6.784$; Critical values: $-2.888(5 \%),-3.492(1 \%)$ ).

For the $q t$ series, the ADF test is -2.953 . Critical values are $-2.888(5 \%)$, $-3.491(1 \%)$. The unit root hypothesis is rejected at $5 \%$ level but not rejected at $1 \%$. For the differenced series $D q t$ the unit root hypothesis is rejected at both levels $(\mathrm{ADF}=-8.76$; critical values are $-2.888(5 \%),-3.492(1 \%))$.

Figure 2 (right panel) shows the scatter plot of the differenced daily average price (DPm) and the differenced daily quantity (Dqt; units are 1000 $\mathrm{Kg})$. Table 2 reports regression parameters. The aggregate slope is negative $(-0.256)$ and statistically significant.

\begin{tabular}{|l|c|c|c|c|}
\hline DPm & Coeff. & Std.Error & t-value & t-prob \\
\hline Constant & 0.021 & 0.075 & 0.284 & 0.777 \\
\hline Dqt & -0.256 & 0.064 & -3.990 & 0.000 \\
\hline
\end{tabular}

Table 2: Regression of DPm versus Dqt.

To ensure that the result here is not affected by such weekly seasonality we also compute the regression using day-of-the-week differences. In other words, every day of the week is differenced compared to the corresponding 

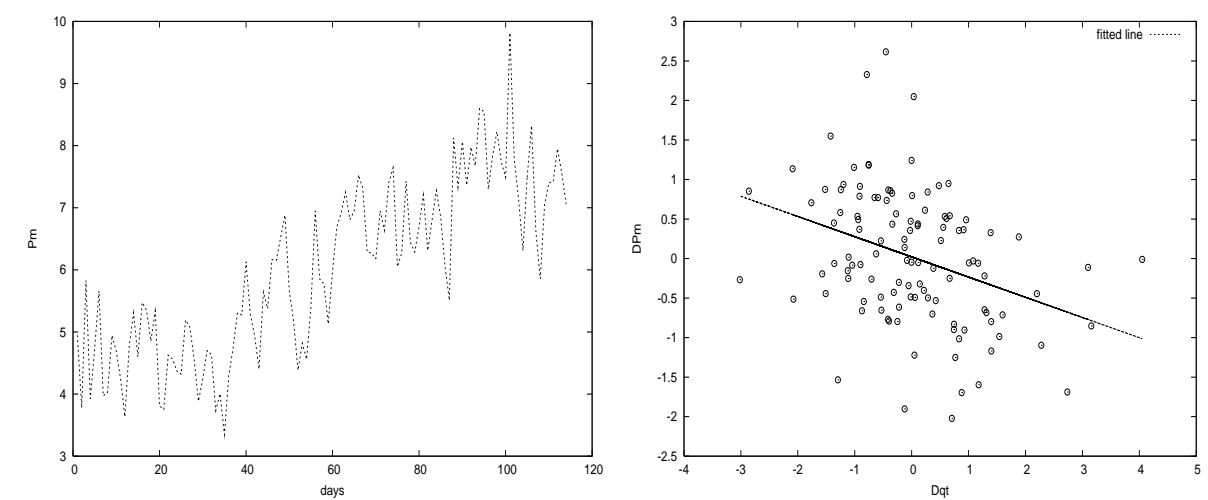

Figure 2: The average (taken over all the TCs) daily price series Pm (left panel). Scatter plot of price-quantity (DPm,Dqt) relation in differences (right panel). A unit of quantity is $1000 \mathrm{Kg}$.

day of the previous week. The regression gives a slope of -3.68 with a tstatistics of -5.39 that, in absolute value, is above the significance level of $1 \%$

This aggregate behavior does not always have a counterpart in the microeconomic data. Indeed plotting the date for a single buyer often yields a rather different picture: price does not matter at low quantity levels. We show this phenomenon in figure 3 (left panel) where we select the days on which one of the largest buyers bought less than $200 \mathrm{Kg}$. of fish. In other cases, when we examine the data for medium size buyers although we observe a reduction in the price volatility for increasing quantities, the price has no trend as seen in the right panel of the same figure. To have a more quantitative insight we ran, for each buyer who realized more than 100 transactions in the period under consideration, (107 buyers) a linear regression between the daily purchased quantity (in kilograms) and the average daily price. 43 of the 107 buyers (about 40\%) resulted to have a positive slope coefficient. We have furthermore selected among the 107 coefficients those which are significantly different from zero at a $10 \%$ confidence level. A positive sign is observed for 21 of the 60 slope coefficients passing the selection (about $35 \%$ ). So the aggregate characteristic, the negative relation between price and quantity, is not a reflection of individual behavior even though this is what standard theory would suggest. 
buyer 78 all T.C.

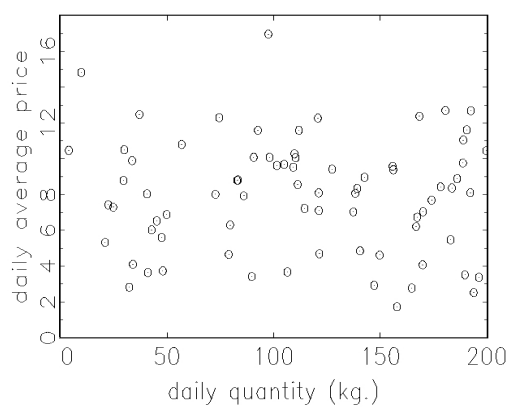

buyer 177 all T.C.

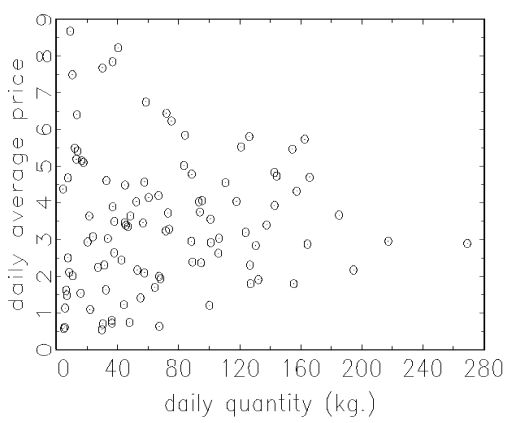

Figure 3: Price-quantity relationship for two buyers, each dot correspond to the observation for a day. Left panel: a large buyer at low quantities. Right panel: a medium buyer.

Our analysis explains the downward sloping price quantity aggregate relationship using agents heterogeneity instead of the more common explanation, based on individual demand derived from utility maximization. From the latter point of view one obtains the aggregate relationship by summing up the corresponding individual functions, but to obtain these individual demand curves one has to rely on a large number of assumptions (all the standard rationality hypotheses, together with the assumption that people successfully find the solution of the corresponding constrained maximization problems, etc).

However, it is possible to obtain the result using only the heterogeneity of the agents. Think of a large number of buyers; each of whom has to buy 1 unit of a good for which they have a reservation price above which they are unwilling to purchase. Their demand curve is vertical but with different heights. So, if, for each level of price, we sum the number of goods demanded we get a downward sloping curve. In this case one gets the same result using very few assumptions. This idea dates back to Cournot and simply requires that individuals have different reservation prices for a unit of the good in question.

More formally in the simple case at hand (where each buyer asks for one 
unit of the good) we can write the demand as

$$
D(P)=\sum_{i} H\left(\bar{P}_{i}-P\right)
$$

Where $H$ is the Heaviside step function, $\bar{P}_{i}$ is buyer's $i$ reservation price, $P$ is the market price and the sum runs over all the buyers. When $P$ increases, the number of buyers having a reservation price higher that $P$ decreases and this implies a downward slope for the aggregate demand function. The shape of the aggregate demand depends on the distribution of the reservation prices. In fact if $F(P):=\operatorname{Pr}\left(\bar{P}_{i}<P\right)$ and $N$ denotes the total number of buyers we have

$$
D(P)=[1-F(P)] N .
$$

\subsection{Price dynamics}

Our next task is to study the evolution of prices over the day. As we have mentioned, basic auction theory suggests that on a given day the price for each unit of a homogeneous good sold sequentially should be the same. Yet, it is often observed that prices decline during the day, yielding the "declining price paradox". Of the many solutions proposed perhaps that closest to our analysis is that proposed by Neugebauer and Pezanis-Christou (2007). They argue that it is uncertainty about the total number of units available which produces the paradox. In our case, the buyers do not know at the beginning of the auction how much is available, but, as the auction progresses, they become more aware of the total. This will be important for our analysis. To analyze the price dynamics during the day we show two types of graph. We first rank the daily transactions by the time of day at which they occurred and then we perform averages for the transactions with the same rank. As shown in figure 4 the average price goes down as the rank of the transactions increases. However, despite this general trend, a strange regularity appears: for a large number of TCs the average price starts increasing for the last transactions, where we will call the time of the closing transaction $T$.

This apparent paradox can be understood by linking the bid setting rule followed by the buyers to the relationship between the changes in prices for the last transactions in a day, and the total quantity of fish sold on that day. What we will show is that the bidding rule will lead buyers to increase their later bids on days when supply is limited. Thus, there should be a negative relation between the changes in prices for the last transactions in a day and the total quantity available. To see this let us examine the bidding rule. 
If a strategy such as "buy the fish at the lowest price" is optimal it must then have a higher value than all other strategies.

For many buyers, who find themselves faced with a transaction at time $T$, it may be optimal to buy even if the price is high when they have not reached the minimum quantity which they wish to obtain in order to satisfy their customers demand.

On days on which buyers begin to perceive that there is a low quantity of fish, it may thus be optimal to buy at higher than average prices starting with a particular transaction before the last one (say at $T-i$ ) since with a limited supply it is likely that waiting for transaction $T$ may result in the buyer's having difficulties in buying the fish that he requires.. In other terms, the value of strategies such as "buy the fish at the lowest price" seems to be lower that that of other strategies and therefore cannot be optimal.

To analyze this intuition suppose that there are only two possible prices, an high price $p_{H}$ and a low price $p_{L}$ with a difference between the two $\Delta=$ $p_{H}-p_{L}$. Furthermore, buyers need only one case of fish.

At every transaction the probability to have the fish at price $p_{H}$ is $p$. The probability to have the fish at price $p_{L}$ is $q<p$.

At transaction $T-i$ the agent computes the expected value of the strategy $L_{i}=$ "try always to buy at the lowest price from $T-i$ to $T$ " with utility equal to $U_{L}(i)=(\Delta+k) I_{q}(i)$. The random variable $I_{q}(i)$ is an indicator variable equal to 1 if the agent get a case from $T-i$ to $T$ and $k$ is a positive constant that could be interpreted as a monetary value from being able to sell the fish to final consumers.

The expected value of this strategy is

$$
E\left[U_{L}(i)\right]=(\Delta+k) E\left[I_{q}(i)\right]
$$

with $^{4}$

$$
E\left[I_{q}(i)\right]=\sum_{n=0}^{i} q(1-q)^{n}=1-(1-q)^{i+1} .
$$

Agents compare strategy $L_{i}$ with the strategy $H_{i}=$ "buy at a high price" with expected utility equal to

\footnotetext{
${ }^{4} I_{q}(i)$ follows a geometric distribution since we can get the fish at the disjoint events "get the fish at $T-i$ ", "not get the fish at $T-i$ and get the fish at $T-i+1$ ", etc.
} 


$$
E\left[U_{H}(i)\right]=k E\left[I_{p}(i)\right]
$$

with

$$
E\left[I_{p}(i)\right]=\sum_{n=0}^{i} p(1-p)^{n}=1-(1-p)^{i+1} .
$$

Strategy $L$ is better than strategy $H$ if

$$
(\Delta+k) E\left[I_{q}(i)\right]>k E\left[I_{p}(i)\right]
$$

that is

$$
E\left[I_{p}(i)\right]-E\left[I_{q}(i)\right]<\frac{\Delta}{k} E\left[I_{q}(i)\right] .
$$

Substituting eqs. 1 and 2 in 3 results in

$$
(1-q)^{i+1}-(1-p)^{i+1}<\frac{\Delta}{k}\left[1-(1-q)^{i+1}\right] .
$$

It is now simple to see that - very far from the last transaction period $T$ - condition 3 is likely to be satisfied since

$$
\lim _{i \rightarrow \infty}\left\{E\left[I_{p}(i)\right]-E\left[I_{q}(i)\right]\right\}=0
$$

and

$$
\lim _{i \rightarrow \infty} E\left[I_{q}(i)\right]=1,
$$

Depending on $\Delta$ and $k$, condition 3 may not be satisfied when we are near the last transaction ( $i$ low). Increasing $i$, the function $E\left[I_{p}(i)\right]-E\left[I_{q}(i)\right]$ increases until a value $i^{*}$ (usually not far from $T$ ) and then decreases.

The value $i^{*}$ can be computed assuming that $i$ is real and evaluating the first order condition of $E\left[I_{p}(i)\right]-E\left[I_{q}(i)\right]$,

$$
(1-q)^{i+1} \ln (1-q)-(1-p)^{i+1} \ln (1-p)=0 .
$$

Assuming that $p$ is low (there are many participants in the auction), so that the usual logarithmic approximation $\ln (1-p) \simeq-p$ applies, the FOC becomes

$$
q(1-q)^{i+1}=p(1-p)^{i+1}
$$


with solution

$$
i^{*}+1=\frac{\ln q-\ln p}{\ln (1-p)-\ln (1-q)} .
$$

In sum, since $E\left[I_{p}(i)\right]-E\left[I_{q}(i)\right]$ increases until a value near $T$ it may be possible that it crosses the threshold $\frac{\Delta}{k} E\left[I_{q}(i)\right]$ making the strategy $H$ better than the $L$ strategy $^{5}$. This may be the case if $k$ is sufficiently high.

In other words, $L$ may not be the optimal strategy for all the transactions. Near the end of the day it may be optimal to buy at a high price.

If the above explanation is correct we would expect a negative relationship between the variation of prices for the last transactions and daily supplied quantity $(q t)$ in situations in which there is a very limited supply of fish and so, where $k$ is high. But, of course this depends on the agents' capacity to anticipate towards the end, how long the auction will last. But this is not implausible since agents are experienced and also have some idea, even if only approximate of the size of the total catch since the fish is stocked at the marketplace overnight. Alternatively it could be the case, that, as time passes, buyers may revise their ideas of $p$ and $q$ (the probability of getting the required fish at the price in question).

We perform regressions at different lags using the difference $P m_{T}-$ $P m_{T-i}$. The result is particularly significant at $i=2$. The limited-supply effect on the last transactions is shown in figure 5 (left panel) where we depict the scatter plot of price variation for the last two transactions, $x=$ $P m_{T}-P m_{T-2}$ versus the daily quantity of fish $q t$. The figure suggests that there is a threshold above and below which the relationship between the changes in the last prices and the daily quantity changes. We may locate the threshold using a simple outlier region (see Davies and Gather, 1993)

$$
\left\{x:\left|x-\mu_{q t}\right|>z_{1-\frac{\alpha}{2}} \sigma_{q t}\right\}
$$

where $\mu_{q t}$ and $\sigma_{q t}$ are mean and standard deviation of $x$ for observations above $q t$. The variable $z_{1-\frac{\alpha}{2}}$ is the usual value of the normal distribution with confidence level $1-\alpha$. Using $1-\alpha=0.9937$ (which corresponds to four standard deviations) and moving $q t$ from right to left we found that the first observation entering the outlier region is at $q t=2.8$.

\footnotetext{
${ }^{5}$ Note also that - reducing $i$ - while $E\left[I_{p}(i)\right]-E\left[I_{q}(i)\right]$ increases, the threshold $\frac{\Delta}{k} E\left[I_{q}(i)\right]$ decreases.
} 

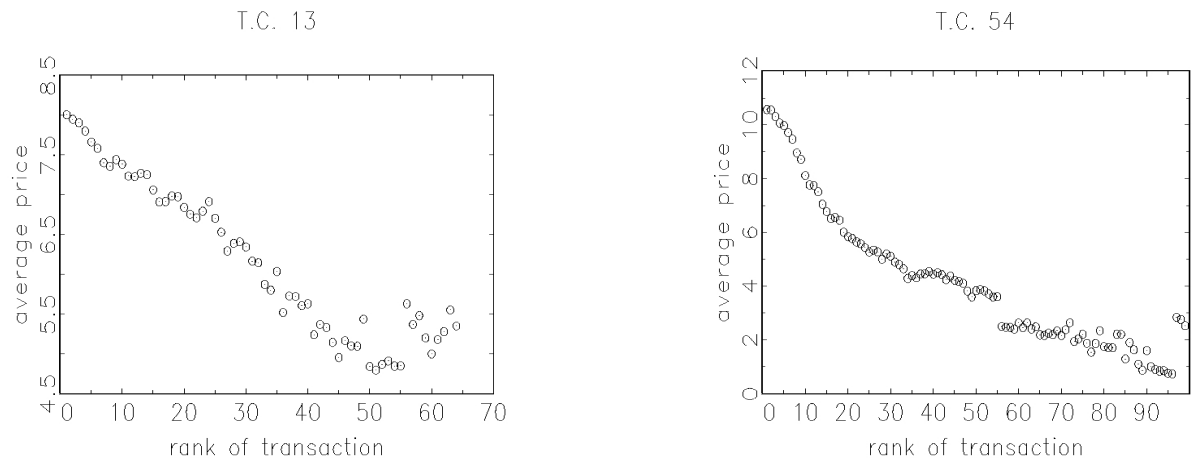

Figure 4: Average price for each rank of transaction (the first dot on the left, for instance, is obtained collecting the price of the first transaction for each day and computing the average).

In the regression, the linear slope increases (in absolute terms) going from -0.4403 , but, in this case, it is not statistically different from zero the $95 \%$ confidence interval being [-1.13708,0.25701], to -2.2648 , a value which is statistically different from zero, the $95 \%$ confidence interval being [-4.22589,0.30377].

Another way to see the threshold effect is to use a non-parametric (kernel) regression drawn in figure 5 (right panel). The regression shows a slope increase (in absolute terms) for daily quantities that are below 2.3.

To summarize, in the Ancona fish market the average price tends to increase for the last transactions on days characterized by a limited supply of fish.

Another type of price dynamics analysis is shown in figure 6 . Here we plot the data corresponding to the day with the largest number of transactions for two TCs (the horizontal axis records the time at which the transaction took place, a value of 4.5 means that the transaction took place at half past 4 in the morning). It is evident in general that the price rises at the beginning and then settles down during the auction. This is due perhaps to the presence of buyers who are obliged to buy very early in the morning for particular reasons (they may have a rather long trip back to their shops or they may have restaurants and have to be present early in order to prepare the meals and so forth). 

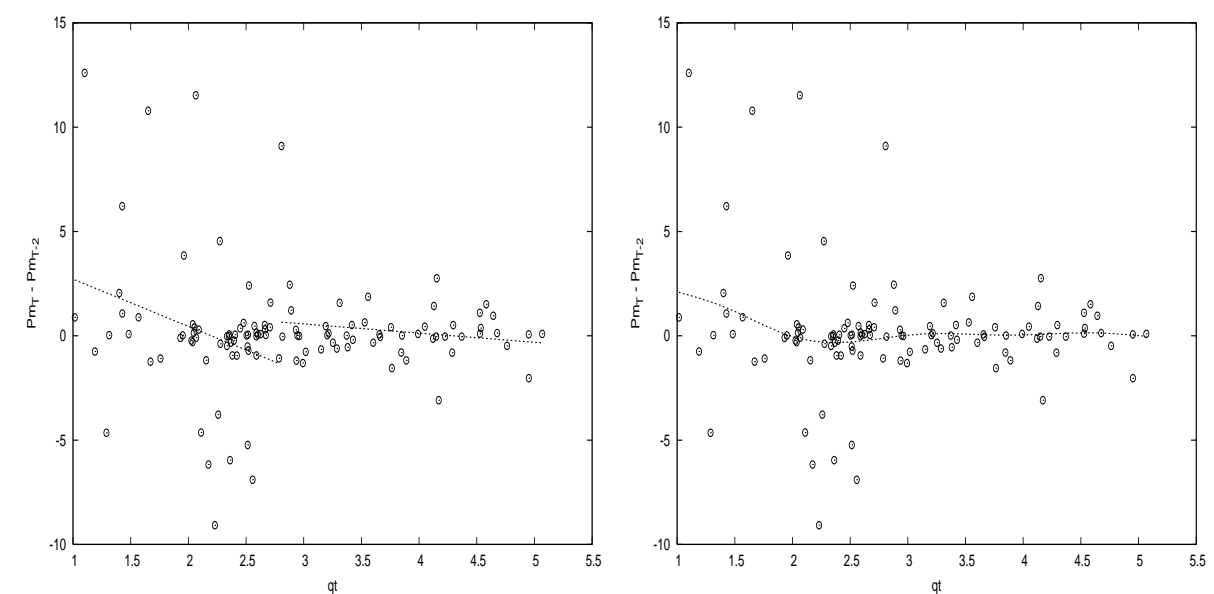

Figure 5: Scatter plot of price variation for the last two transactions, $P m_{T}-P m_{T-2}$ versus daily quantity of fish $q t$. The left panel show a piecewise linear regression using the threshold $q t=2.8$ whereas in the right panel a non-parametric regression with Gaussian kernel and bandwidth 0.4 is drawn.

In figure 7 we normalize the trading interval setting the starting minute to " $t=0$ " and the end of trading to " $t=1$ ". The graph shows the quantity traded by buyers leaving the market after a given time $t=\bar{t}$ (for example, there are 105 buyers out of a total of 149 who left the market after $t=0.48$ and hence 44 who left earlier).

The pattern suggests that the decline in demand is not linear. Instead there is an acceleration in the fall of the traded quantity at about $t=0.4$.

Another question and one which is very old in the analysis of fish markets, is the dependence of the price level on the day of the week.

In table 3 we re-compute the regression whose results are displayed in table 2 adding 3 dummy variables for Tuesdays (d2), Wednesdays (d3), and Thursdays (d4). The value of the coefficients for these give the day effect compared to Fridays. The table shows that the dummy variable for Tuesdays is positive, meaning that the price is statistically higher than on Fridays. However, it then falls on Wednesdays and Thursdays (or, to be precise, does not rise, since $\mathrm{d} 4$ is not significant) and then recovers (at least compared to Wednesdays) on Fridays even though it does not return to the Tuesday level.

In other terms, fish is more expensive at the beginning of the week while the "Friday effect" (for a long period families in Catholic countries were 
T.C. 12 (8th Apr 03)

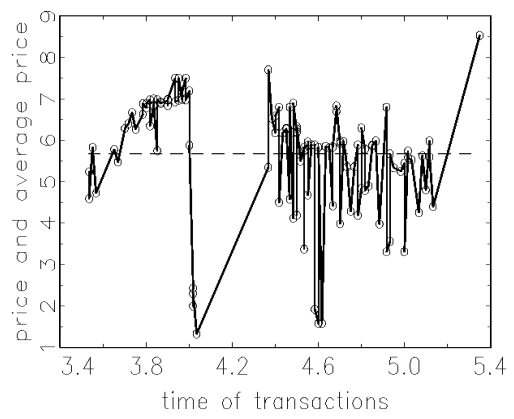

T.C. 54 (22th Nov 02)

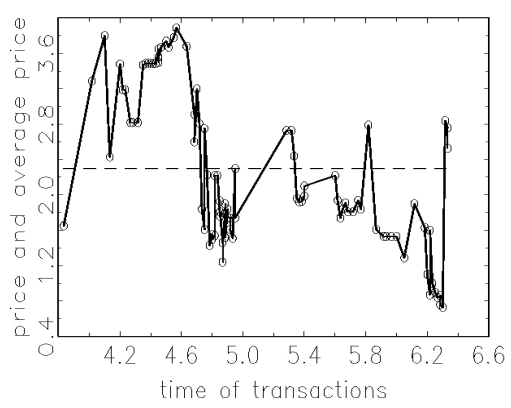

Figure 6: Price dynamics in a given day.

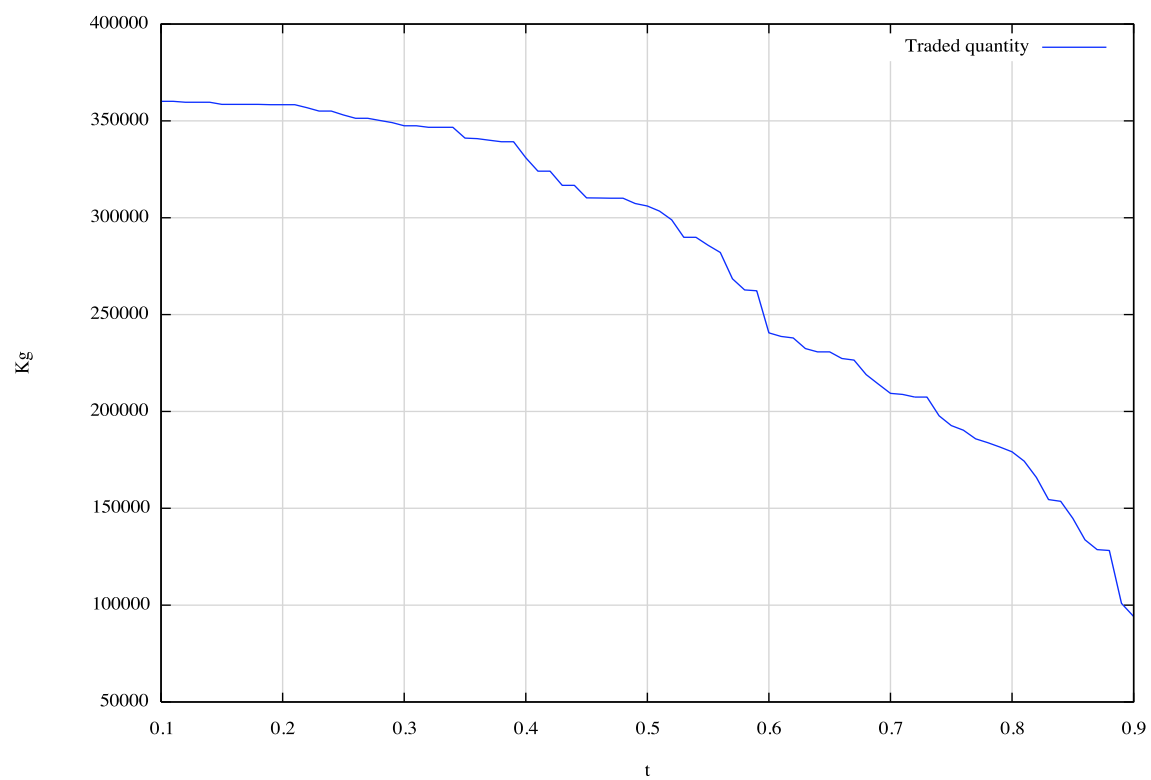

Figure 7: Total traded quantity at each time in the market day. 
exhorted by the church to eat fish on Fridays) is not so evident (even though the price tends to increase compared to Wednesdays). ${ }^{6}$ Lionel Robbins (1935) made the following remark about the reformation in the U.K which replaced Catholicism with Anglicanism, "The influence of the Reformation made no change in the forces of gravity. But it certainly must have changed the demand for fish on Fridays".

\begin{tabular}{|l|c|c|c|c|}
\hline DPm & Coeff. & Std.Error & t-value & t-prob \\
\hline Constant & 0.061 & 0.132 & 0.459 & 0.647 \\
\hline Dqt & -0.315 & 0.060 & -5.300 & 0.000 \\
\hline d2 & 0.499 & 0.194 & 2.570 & 0.011 \\
\hline d3 & -0.505 & 0.191 & -2.650 & 0.009 \\
\hline d4 & -0.134 & 0.191 & -0.705 & 0.483 \\
\hline
\end{tabular}

Table 3: Regression of DPm versus Dqt with dummy variables for the day of the week. Tuesday (d2), Wednesday (d3), and Thursday (d4). Their value gives the day effect compared to Friday.

\subsection{Loyalty}

We now turn to another very interesting question which is to ascertain whether the auction mechanism destroys buyer-seller relationships. Indeed Weisbuch et al. 2002 found evidence of loyalty of buyers to sellers in the Marseille fish market, but there the market is characterized by bilateral bargaining. In that case, every buyer could, in principle, collect every seller's price and then choose his best action. However many do not do so, or at least cease to do so as they become loyal to one seller. What is interesting in the case of Ancona is that buyers still learn to become loyal as they do in Marseille. Loyalty in the Ancona case is loyalty to a fishing vessel with whom, naturally, the buyers have no contact. However, they do have their past experience with the fish brought from that vessel as a guide to the desirability of buying from that seller, and this can, as in the Marseille case, lead to reinforcement learning.

How then should we test for loyalty? A statistical test for showing the (lack of) connection between buyers and sellers is the chi-square test of independence made on the contingency table recording the number of exchanges

\footnotetext{
${ }^{6}$ The absence of a "Friday effect" could be a consequence of the secularization of the Italian society together with the removal of the church's injunction.
} 
between each buyer and each seller. their respective distributions. Under the null hypothesis agents match in a random way so there is no loyalty. To avoid the size-problem, i.e. the fact that buyers and sellers trading greater quantity are more likely to meet, we group buyers and sellers into two and three groups respectively that are homogeneous with respect to traded quantity. In other words, buyers with id-number between 1 and 140 buy the same quantity as those between 141 and 303. Similarly, sellers are split in the two groups 1-82 and 83-154. The contingency table of the 2-groups partition is reported in table 4 .

\begin{tabular}{|l||c|c|}
\hline $\begin{array}{l}\text { Buyers } \rightarrow \\
\text { Sellers } \downarrow\end{array}$ & $1-82$ & $83-154$ \\
\hline \hline $1-140$ & 12928 & 13675 \\
\hline $141-303$ & 13324 & 13582 \\
\hline
\end{tabular}

Table 4: Contingency table of the 2-groups partition. Number of transactions between buyers and sellers.

For the 3 groups case, a homogeneous partition is: sellers $=[1-95,96-$ $177,178-303]$; buyers $=[1-60,61-111,112-154]$. The contingency table is reported in table 5 .

\begin{tabular}{|l||c|c|c|}
\hline $\begin{array}{l}\text { Buyers } \rightarrow \\
\text { Sellers } \downarrow\end{array}$ & $1-95$ & $96-177$ & $178-303$ \\
\hline \hline $1-60$ & 5750 & 5607 & 5904 \\
\hline $61-111$ & 6104 & 5936 & 6046 \\
\hline $112-154$ & 6331 & 5611 & 6220 \\
\hline
\end{tabular}

Table 5: Contingency table of the 3-groups partition. Number of transactions between buyers and sellers.

The chi-square test statistic is 4.5752 ( $\mathrm{p}$-value $=0.032438$ ) for the 2groups case and 20.850 ( $\mathrm{p}$-value $=0.000339)$ for the 3 -groups case showing that the hypothesis of random matching between buyers and sellers has to be rejected in both cases at the $5 \%$ significance level and, for the 3-groups case, also at the $1 \%$.

Then we calculated the Gini index for each buyer ${ }^{7}$. In figure 8 below we

\footnotetext{
${ }^{7}$ the Gini index is a measure of how concentrated a distribution is. In our case the
} 
buyer $198 \quad(G=0.175)$

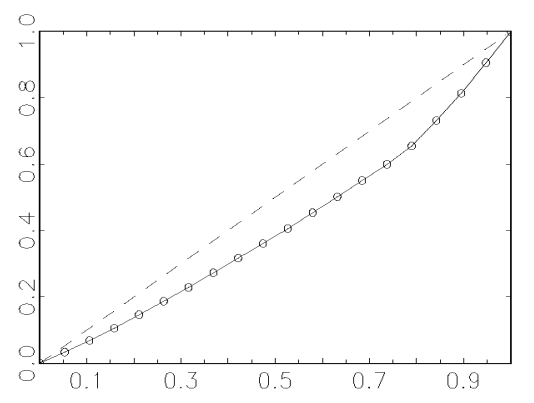

buyer $296(G=0.606)$

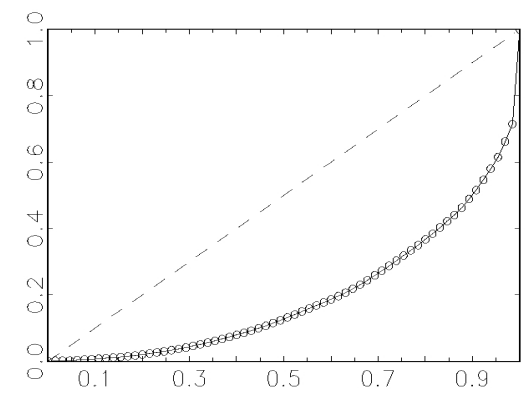

Figure 8: Lorenz curves for two buyers.

show the Lorenz curve for the two extreme cases (the least concentrated in the left panel and the most concentrated in the right one).

To have a global picture of the extent of loyalty in the market we made a smoothed (Gaussian kernel) frequency distribution of the Gini index among buyers. A significant share of buyers have a Gini index around 0.4 and almost all have their index between 0.35 and 0.55 .

The buyer-seller relationship is different from that in the Marseille fish market. There Weisbuch et al. (2002) find basically two type of agents: the loyal ones and the ones who seem to choose their seller at random. The auction mechanism appears to eliminate the second kind of buyer since the distribution in figure 9 is single peaked.

Next we investigate the dependence of loyalty on the buyer's size. Figure 10 shows that the amount of loyalty increases with the size of the buyers up to a given value. Beyond this level, the concentration index decreases or stays stable; this is probably because very large buyers are forced to rely on multiple sources for their fish if they are to acquire enough.

\subsection{Buyers and Sellers Price performance}

In this section we examine the extent to which some market participants do better, have a better "price performance", than others. Let us first clarify

index equals 1 if the buyer buys from only one buyer and equals 0 if the buyer buys from each of the $n$ sellers he is a customer with a share $1 / n$ of the total fish bought . 
distribution of Gini index

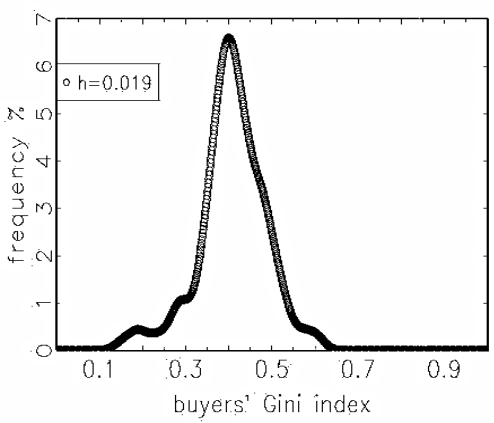

Figure 9: Loyalty. whole period, all TCs

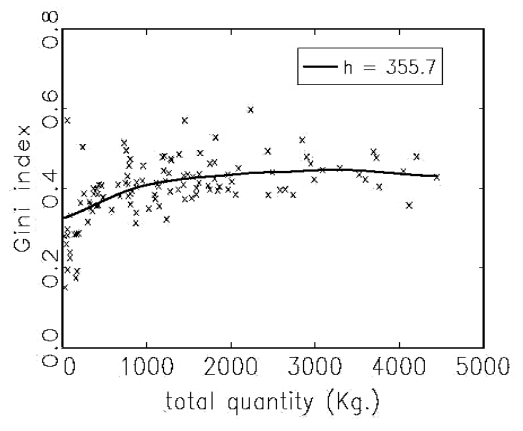

Figure 10: Relationship between buyers size and their loyalty, each dot is a buyer.

what we mean by the expression "price performance". In what follows it refers to the average price, so that a buyer has a good price performance if he usually buys at a relatively low price, on the contrary, a seller has a good price performance if he sells at a relatively high price. We undertake this analysis to test the hypothesis of market efficiency. In an efficient market, it should not be the case that an agent can systematically obtain more favorable prices for the same products than other agents so that finding systematically good or bad price performances for some individual may be regarded as a symptom of market inefficiency.

The first question here is: are price performances related to the amount of fish transacted? ${ }^{8}$ Figures 11 and 12 provide an answer. Basically it seems that the amount of fish bought or sold has no influence on price performances. This conclusion is robust for buyers while for sellers we can observe that the large ones never sold at an average price lower than $7 \in$, while some of the smaller ones sold at a lower average price.

So to find out if there are some buyers who pay higher (lower) prices than

\footnotetext{
${ }^{8}$ Of course the quality of fish is also important for our analysis. Unfortunately there is no way to have this information from the dataset. One argument would be that those who pay systematically lower prices simply buy fish of lower quality. However, discussion with the market organizers and participants suggest that the variability of quality is too low to account for the differences that we observe.
} 

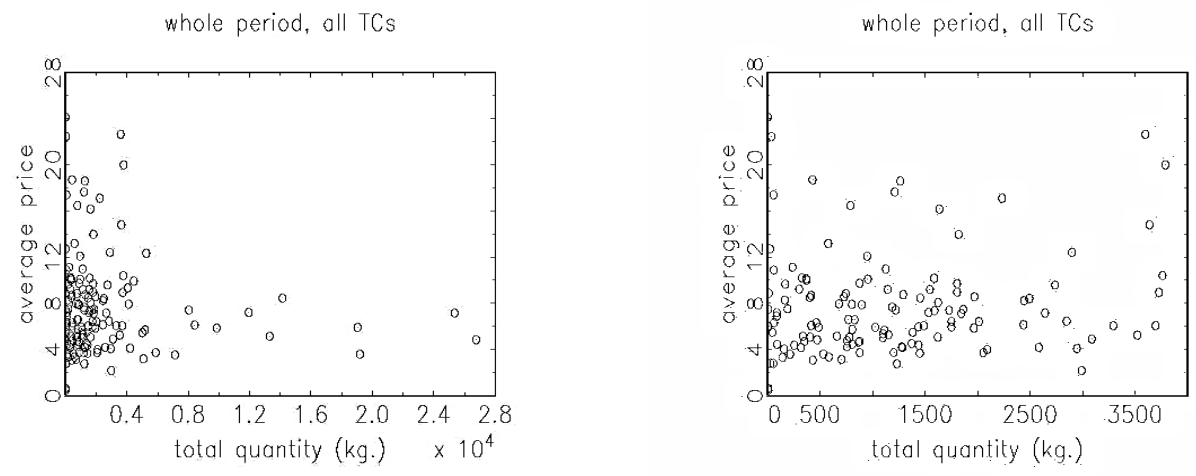

Figure 11: Buyers' price performances. All buyers (left), buyer with a purchased quantity lower than $4000 \mathrm{Kg}$. (right) this is basically a zoom on the low quantity of the graph on the left.

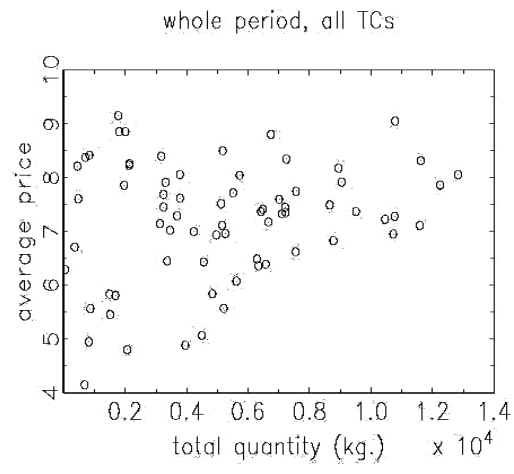

Figure 12: Sellers price performances. 
others or some vessels getting higher (lower) prices than others we perform a more sophisticated exercise. The analysis proceed as follows. For each subject (buyer or seller), we calculate the monthly average price and rank the subject by his price (prices are taken in increasing order). For each month, we thus associate the number one to the subject with the lowest price, two to the one with second lowest price and so on. Because the data cover 9 months, subjects who were always present on the market have a vector of 9 numbers denoting their ranks. If subject $\mathrm{X}$ has the vector $[12,5, .$.$] this$ means that there were eleven other people with an average price lower than his average price in September, four people having a lower average price on October and so on. To evaluate the performance of the subject we establish a threshold (ten in the following exercises) and count the number of times the rank of the subject was less than or equal to the threshold. In tables 6-9 we denote the number of successes in this procedure with $s$, the number of months the agent was present on the market with $p$ and his rank with $r$. If we consider the average price for all the agent's transactions over the whole period and all TCs, the price column indicates the average price and quantity refers to the total quantity. So from table 6 we can see for example that buyer 271 was present for all the nine months; in all the nine months his monthly average price was among the ten lowest average prices. He bought $2991 \mathrm{Kg}$. of fish during the whole period at an average price slightly higher than two Euros and this was the third lowest average price. Furthermore, the same buyer had good results on the single TCs: for eight months (out of nine) he bought small sole (TC 12) at an average price which was one of the ten lowest average prices recorded for that TC; and in four months out of six buying big hake (TC 13). According to table 6 there are several buyers who perform better than others even for particular TCs (for example buyers 164, $271,153,177,169,1)$. Table 7 reports buyers with poor performance (those having a rank higher than 100). Buyers 90, 91 and 84 have particularly poor performances. Tables 8 and 9 relate to sellers. The first ones indicates sellers who perform well (who sell at high prices and have a high rank). Sellers with high price are 148, 83, 30, 138, 134 and 66, while those with low prices are 103 and 48 .

In general these results confirm the presence of agents who systematically perform better than others indicating that the market may, to some extent, be inefficient. An argument often used to explain differences in the prices obtained by the participants in certain markets is that their creditworthiness may vary. However, on the Ancona market all transactions are paid for 


\begin{tabular}{|c|c|c|c|c|c|c|c|c|c|c|c|}
\hline \multicolumn{6}{|c|}{ all TCs } & \multicolumn{3}{|c|}{ TC 12} & \multicolumn{3}{|c|}{ TC 13} \\
\hline ID & $s$ & $p$ & $r$ & price & quantity & ID & $s$ & $p$ & ID & $s$ & $p$ \\
\hline 164 & 9 & 9 & 7 & 3.0778 & 430 & 271 & 8 & 9 & 169 & 6 & 7 \\
\hline 271 & 9 & 9 & 3 & 2.178703 & 2991.52 & 164 & 6 & 8 & 271 & 4 & 6 \\
\hline 170 & 8 & 9 & 4 & 2.769652 & 1231.99 & 165 & 4 & 7 & 187 & 3 & 6 \\
\hline 176 & 7 & 9 & 17 & 3.725731 & 2054.42 & 105 & 3 & 9 & 155 & 3 & 6 \\
\hline 258 & 7 & 9 & 11 & 3.350421 & 581.84 & 221 & 3 & 7 & 237 & 3 & 6 \\
\hline 153 & 7 & 8 & 10 & 3.309 & 140.92 & 241 & 3 & 5 & 281 & 2 & 7 \\
\hline 177 & 6 & 9 & 12 & 3.522101 & 7129.71 & 177 & 3 & 9 & 153 & 2 & 5 \\
\hline 259 & 6 & 9 & 26 & 4.163261 & 317.77 & 101 & 3 & 7 & 138 & 2 & 7 \\
\hline 169 & 6 & 9 & 16 & 3.678469 & 1449.74 & 178 & 3 & 6 & 1 & 2 & 7 \\
\hline 1 & 5 & 8 & 13 & 3.579412 & 19177.11 & 278 & 2 & 5 & 130 & 2 & 7 \\
\hline
\end{tabular}

Table 6: Buyers with good price performances.

\begin{tabular}{|rrrrrr||rrr||rrr|}
\hline \multicolumn{7}{|c||}{ all TCs } & \multicolumn{3}{|c||}{ TC 12} & \multicolumn{3}{|c|}{ TC 13} \\
\hline ID & $s$ & $p$ & $r$ & price & quantity & ID & $s$ & $p$ & ID & $s$ & $p$ \\
\hline \hline 75 & 9 & 9 & 148 & 22.65029 & 3599.64 & 269 & 6 & 7 & 201 & 7 & 9 \\
84 & 9 & 9 & 130 & 10.96837 & 1125.12 & 91 & 6 & 6 & 84 & 6 & 9 \\
270 & 9 & 9 & 144 & 18.58776 & 1261.83 & 90 & 5 & 6 & 267 & 6 & 7 \\
106 & 9 & 9 & 145 & 18.71657 & 427.93 & 263 & 5 & 6 & 90 & 6 & 8 \\
188 & 8 & 9 & 141 & 17.10356 & 2235.15 & 199 & 4 & 7 & 279 & 5 & 9 \\
195 & 8 & 9 & 137 & 13.97355 & 1818.57 & 273 & 4 & 6 & 186 & 5 & 9 \\
82 & 7 & 9 & 139 & 16.18111 & 1634.21 & 162 & 4 & 7 & 91 & 5 & 7 \\
148 & 7 & 9 & 132 & 12.09021 & 947.61 & 117 & 4 & 7 & 121 & 5 & 8 \\
156 & 7 & 9 & 140 & 16.46758 & 788.25 & 217 & 4 & 7 & 87 & 5 & 8 \\
281 & 7 & 8 & 138 & 14.8035 & 3638.49 & 267 & 4 & 7 & 272 & 4 & 6 \\
\hline
\end{tabular}

Table 7: Buyers with bad price performances. 


\begin{tabular}{|rrrccr||rrr||rrr|}
\hline \multicolumn{1}{|c||}{ all TCs } & \multicolumn{3}{|c||}{ TC 12 } & \multicolumn{3}{|c|}{ TC 13} \\
\hline ID & $s$ & $p$ & $r$ & price & quantity & ID & $s$ & $p$ & ID & $s$ & $p$ \\
\hline \hline 138 & 6 & 9 & 66 & 8.802716 & 6741.73 & 148 & 3 & 8 & 30 & 6 & 7 \\
83 & 4 & 9 & 48 & 7.745368 & 7559.3 & 81 & 3 & 5 & 123 & 6 & 6 \\
148 & 4 & 9 & 60 & 8.315651 & 11615.91 & 139 & 3 & 6 & 66 & 5 & 9 \\
121 & 4 & 8 & 58 & 8.230408 & 2130.33 & 83 & 3 & 8 & 67 & 5 & 9 \\
30 & 4 & 7 & 61 & 8.349025 & 7239.03 & 134 & 3 & 7 & 145 & 6 & 7 \\
126 & 4 & 9 & 55 & 8.056547 & 3779.51 & 100 & 3 & 5 & 22 & 4 & 7 \\
146 & 3 & 7 & 65 & 8.499142 & 5170.71 & 38 & 2 & 7 & 138 & 4 & 7 \\
45 & 3 & 7 & 51 & 7.910356 & 3315.49 & 122 & 1 & 7 & 118 & 4 & 8 \\
134 & 3 & 9 & 69 & 9.051084 & 10780.86 & 113 & 1 & 7 & 37 & 4 & 9 \\
66 & 3 & 9 & 63 & 8.394254 & 3173.71 & 129 & 1 & 7 & 105 & 4 & 7 \\
\hline
\end{tabular}

Table 8: Sellers with good price performances.

\begin{tabular}{|rrrrrr||rrr||rrr|}
\hline \multicolumn{1}{|c||}{ all TCs } & \multicolumn{3}{c||}{ TC 12 } & \multicolumn{3}{c|}{ TC 13} \\
\hline ID & $s$ & $p$ & $r$ & price & quantity & ID & $s$ & $p$ & ID & $s$ & $p$ \\
\hline \hline 82 & 6 & 7 & 2 & 4.8025 & 2068.47 & 95 & 8 & 8 & 52 & 6 & 6 \\
103 & 6 & 7 & 3 & 4.880414 & 3952.92 & 143 & 8 & 9 & 69 & 6 & 6 \\
145 & 6 & 9 & 8 & 5.567217 & 5204.89 & 44 & 7 & 8 & 44 & 5 & 7 \\
110 & 6 & 7 & 5 & 5.066325 & 4492.81 & 78 & 6 & 8 & 136 & 5 & 5 \\
67 & 5 & 9 & 14 & 6.361449 & 6332.92 & 136 & 6 & 8 & 58 & 5 & 5 \\
139 & 5 & 8 & 25 & 6.996613 & 4232.68 & 113 & 6 & 7 & 143 & 5 & 7 \\
56 & 4 & 5 & 7 & 5.562541 & 872 & 48 & 5 & 5 & 83 & 4 & 5 \\
113 & 4 & 9 & 10 & 5.832403 & 1489.01 & 58 & 5 & 8 & 129 & 4 & 8 \\
130 & 3 & 9 & 11 & 5.83739 & 4837.3 & 134 & 3 & 7 & 148 & 3 & 5 \\
48 & 3 & 5 & 1 & 4.14284 & 681.45 & 122 & 3 & 7 & 96 & 3 & 9 \\
\hline
\end{tabular}

Table 9: Sellers with bad price performances. 
through a clearing mechanism at the end of each day so there is no credit.

\subsection{Loyalty and price performances}

We analyze in this section the relationship between buyers price performances and loyalty by collecting the number of matches $n_{(i, j)}$ between buyer $i$ and seller $j$ (as a measure of loyalty) and the average unitary price $p_{(i, j)}$ of the case.

To avoid biases in the estimation due to the clear heterogeneity in the panel, we estimate the two following fixed effect equations

$$
p_{(i, j)}-\mu_{i}=\alpha_{1}+\beta_{1} n_{(i, j)}+\varepsilon_{(i, j)}
$$

and

$$
p_{(i, j)}-\mu_{j}=\alpha_{2}+\beta_{2} n_{(i, j)}+\epsilon_{(i, j)} .
$$

The parameter $\mu_{i}=n_{i}^{-1} \sum_{j} p_{(i, j)}$ varies across buyers $\left(n_{i}\right.$ is the number of matches made by buyer $i$ ). It captures the heterogeneity in buyer's price (e.g., differences in reservation prices), whereas $\mu_{j}=n_{j}^{-1} \sum_{i} p_{(i, j)}$ differs across sellers $\left(n_{j}\right.$ is the number of matches made by seller $\left.j\right)$. It captures the heterogeneity in seller's price (e.g., differences in the quality of fish sold).

The estimates are reported in table 10.

\begin{tabular}{|c|c|c|c|c|}
\hline & estim. eq. 4 & st.dev eq. 4 & estim. eq. 5 & st.dev 5 \\
\hline$\alpha$ & 0.2054 & 0.1198 & 0.8606 & 0.2149 \\
\hline$\beta$ & $-0.0089\left(^{*}\right)$ & 0.0041 & $-0.0371(* *)$ & 0.0073 \\
\hline
\end{tabular}

Table 10: Estimates of equations 4 and 5. The asterisk $\left(^{*}\right)$ means "stat. sign. at 5\%" whereas the $(* *)$ means "stat. sign. at $1 \%$ ".

Estimates of equations 4 and 5 show - albeit with different levels of confidence - that loyalty results in an average reduction of the unitary price payed. This result is in contrast to that observed in the pairwise trading situation where loyal customers pay more. A possible explanation is that in markets organized as Dutch auctions there is no direct relation between buyers and sellers thus the sort of co-evolution in which buyers and sellers learn their mutual needs and which is observed on the Marseille market cannot occur. The reward for loyalty is probably due to the complex learning process that emerges from transactions, but this is not the same as when buyers and sellers meet face to face. For example, in the pairwise situation customers could 
be willing to pay something more to get preferential service (for example to get priority from the seller when there is a low supply), but this cannot happen in the auction market. In an agent based model developed in Kirman and Vriend (2001) the authors found that loyal buyers paid more but they had fewer visits to sellers where their demand was not satisfied.

\section{Conclusions}

In this paper we have investigated a certain number of questions concerning the functioning of the fish market in Ancona (MERITAN). As we pointed out, in the introductory section, fish markets have long been studied because they present a large range of allocation mechanisms (pairwise interactions, English auctions, Dutch auctions, etc.) and because of the perishable nature of the good exchanged.

At the MERITAN, transactions take place by means of three simultaneous Dutch auctions.

The main question is to what extent the fact that the market is organized through Dutch auctions, affects buyers' behavior. Does it diminish the ability of a buyer to perform well in terms of the prices of the transactions he makes? How do customer seller relationships change with respect to other types of market organization under this price setting mechanism? Evidence from the data show that buyer-seller relationships are less strong than in a pairwise bargaining market such as the Marseille Fish market but a remarkable amount of loyalty is still present even under the auction mechanism. Furthermore, loyalty seems to be negatively related to unitary price paid in contrast to what was observed on the Marseille fish market. This result may seem quite obvious in a normal trading situation. However, in this kind of auction there is no direct relation between buyers and sellers. The fact that some buyers may learn to pay lower prices may be the result of the rather complicated reinforcement learning process that takes place over time.

We also explain the "declining price paradox" for the Ancona fish market by linking the bid setting rule used by the buyers to the relationship between the changes in the prices of the last transactions of the day and the total quantity of fish sold on that day. In particular we observed that the average price tends to increase for the last transactions on days on which there was a limited supply of fish.

This work is a modest contribution to the literature concerning agents' behavior in markets. We intend to pursue our investigation of this topic in 
the future by gathering other detailed datasets and by systematically integrating them with our existing ones to build a more complete picture of the relationship between the behavior of market participants and types of market organization.

\section{Acknowledgements}

We gratefully acknowledge comments and suggestions from the participants of the workshop "The Emergence and Impact of Market Institutions: The Market for Fish and other Perishable Commodities", Troms $\varnothing$ (Norway), 5-6 July 2007, and two anonymous referees for their helpful comments. We also acknowledge funding from the European Commission projects, Complex Markets and DIME.

\section{References}

Ashenfelter, O. C., 1989. How auctions work for wine and art. Journal of Economic Perspectives 3, 23-36.

Bulow, J., Klemperer, P., 1996. Auctions versus negotiations. American Economic Review 86 (1), 180-194.

Davies, L., Gather, U., 1993. The identification of multiple outliers. Journal of the American Statistical Association 88 (423), 782-792.

Ekelund, R., Thommesen, S., 1989. Disequilibrium theory and thornton's assault on the laws of supply and demand. History of Politica Economy $21,567-592$.

Hardle, W., Kirman, A. P., 1995. Nonclassical demand. a model-free examination of price-quantity relations in the marseille fish market. Journal Of Econometrics 67, 227-257.

Kirman, A., Vriend, N., 2001. Evolving Market Structure: An ACE Model of Price Dispersion and Loyalty. Journal of Economic Dynamics and Control $25(3-4), 459-502$.

List, J. A., 2004. Testing neoclassical competitive theory in multilateral decentralized markets. Journal of Political Economy 112, 1131-1156. 
Lu, X., McAfee, R., 1996. The evolutionary stability of auctions over bargaining. Games and Economic Behavior 15 (2), 228-254.

McAfee, R., McMillan, J., 1987. Auctions and bidding. Jounal of Economic Literature 25, 699-738.

McAfee, R., Vincent, D., 1993. The declining price anomaly. Journal of Economic Theory 60, 191-212.

Mill, J. S., 1869. Thornton on labor and its claims. Fortnightly Review.

Myerson, R., Satterthwaite, M., 1983. Efficient mechanisms for bilateral trading. Journal of Economic Theory 29 (2), 265-281.

Negishi, T., 1986. Thornton's criticism of equilibrium theory an mill. History of Political Economy 18, 567-577.

Negishi, T., 1989. On equilibrium and disequilibrium - a reply to ekelund and thommesen. History of Political Economy 21, 593-600.

Neugebauer, T., Pezanis-Christou, P., 2007. Bidding behavior at sequential first-price auctions with(out) supply uncertainty: A laboratory analysis. Journal of Economic Behavior and Organization 63 (1), 55-72.

Progrebna, G., 2006. Auctions, versus bilateral bargaining: Evidence from a natural experiment, available at SSRN: http://ssrn.com/abstract $=954891$.

Robbins, L., 1935. An Essay on the Nature and Significance of Economic Science. Macmillan, London.

Smith, V. L., 1964. Effect of market organization on competitive equilibrium. Quarterly Journal of Economics 78 (2), 182-201.

Thornton, W. H., 1870. On Labour, Its wrongful claims and rightful dues, its actual present and possible future, 2nd Edition. Mcmillan, London.

Volterra, V., 1926. Fluctuations in the abundance of a species considered mathematically. Nature 118, 558-560.

Weisbuch, G., Kirman, A., Herreiner, D., 2000. Market organization and trading relationships. The Economic Journal 110 (463), 411-436. 